\title{
Predictive images of postoperative levator resection outcome using image processing software
}

This article was published in the following Dove Press journal:

Clinical Ophthalmology

27 September 2016

Number of times this article has been viewed

\section{Yuki Mawatari ${ }^{1}$ \\ Mikiko Fukushima² \\ 'Igo Ophthalmic Clinic, Kagoshima, 2Department of Ophthalmology, Faculty of Life Science, Kumamoto University, Chuo-ku, Kumamoto, Japan}

Video abstract

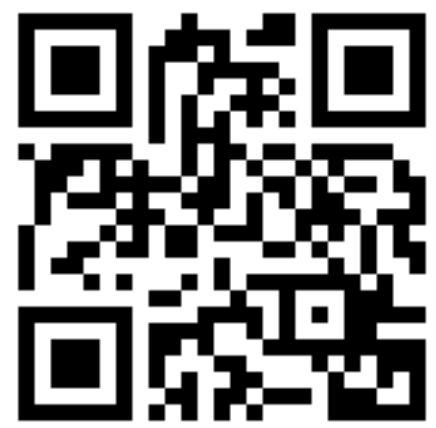

Point your SmartPhone at the code above. If you have a QR code reader the video abstract will appear. Or use: http://youtu.be/0-nQkFXhPEQ
Correspondence: Yuki Mawatari Igo Ophthalmic Clinic, 7-I0 Yamashitacho, Kagoshima 892-0816, Japan

Tel +8I 992273000

Fax +8I 992270555

Email yukz918@igoganka.or.jp
Purpose: This study aims to evaluate the efficacy of processed images to predict postoperative appearance following levator resection.

Methods: Analysis involved 109 eyes from 65 patients with blepharoptosis who underwent advancement of levator aponeurosis and Müller's muscle complex (levator resection). Predictive images were prepared from preoperative photographs using the image processing software (Adobe Photoshop ${ }^{\circledR}$ ). Images of selected eyes were digitally enlarged in an appropriate manner and shown to patients prior to surgery.

Results: Approximately 1 month postoperatively, we surveyed our patients using questionnaires. Fifty-six patients $(89.2 \%)$ were satisfied with their postoperative appearances, and 55 patients $(84.8 \%)$ positively responded to the usefulness of processed images to predict postoperative appearance.

Conclusion: Showing processed images that predict postoperative appearance to patients prior to blepharoptosis surgery can be useful for those patients concerned with their postoperative appearance. This approach may serve as a useful tool to simulate blepharoptosis surgery.

Keywords: levator resection, blepharoptosis, image processing, Adobe Photoshop ${ }^{\circledR}$

\section{Introduction}

The predominant aim of blepharoptosis surgery is to improve visual fields or visual function. However, this technique can remarkably alter postoperative appearance. In our experience, many patients were worried about their postoperative appearance when receiving an explanation on the surgery.

Accordingly, this study aims to evaluate the efficacy of processing preoperative photographs using image processing software (Adobe Photoshop ${ }^{\circledR}$, San Jose, CA, USA) to show patients how they are likely to appear following blepharoptosis surgery.

\section{Methods}

\section{Subjects}

This study included 109 eyes from 65 patients with blepharoptosis who underwent levator resection at Igo Ophthalmic Clinic between August 2015 and March 2016. Eight males and 57 females with a mean age of 60.4 years (range 39-90 years) were recruited. Forty-four patients had bilateral blepharoptosis, and 21 had unilateral blepharoptosis. Patients for whom clear postoperative images could not be created were excluded from this study.

The causes of blepharoptosis in our patient cohort included the prolonged use of hard contact lens (50 eyes, 76.9\%), aging (eleven eyes, 16.9\%), congenital blepharoptosis 
(three eyes, 4.6\%), and trauma (one eye, 1.5\%). Although levator function was good in 105 eyes, poor levator function $(<2 \mathrm{~mm})$ was noted in three eyes with congenital blepharoptosis and in one eye with age-related blepharoptosis.

This study was conducted in accordance with the Declaration of Helsinki and with the approval of the Igo Ophthalmic Clinic's ethical review board, and prior written informed consent was obtained from each patient.

\section{Surgical procedure (levator resection)}

The levator resection involved several steps. First, we made a skin excision line along the upper eyelid skin crease at approximately $4 \mathrm{~mm}$ from the upper eyelid margin and administered a local anesthetic solution into the subcutaneous and conjunctival fornix.

The marked skin was then incised with a laser blade, and the eyelid was fixed with S-485 Entropion Forceps Kuhnt (Inami \& Co., Ltd., Tokyo, Japan). Subsequently, the orbicularis muscle was dissected with scissors and the levator aponeurosis was visualized. Then, the levator aponeurosis was detached from the tarsus (Figure 1A), and the levator aponeurosis and Müller's muscle complex were separated together from the palpebral conjunctiva (Figure 1B).
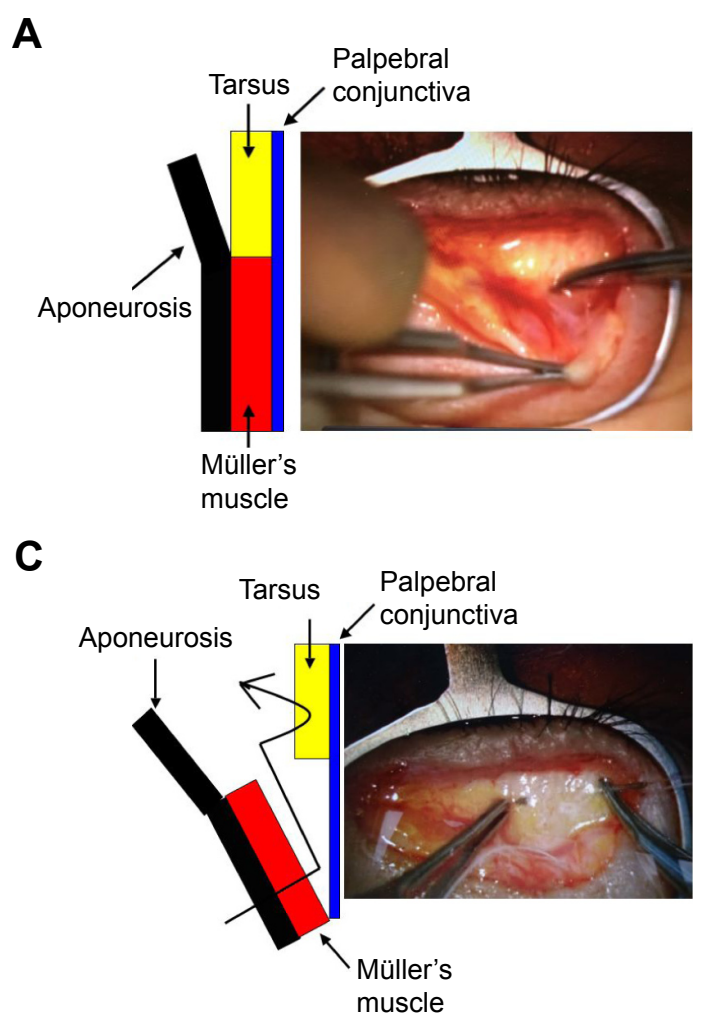

Mattress suturing was performed using 6-0 Vicryl ${ }^{\circledR}$ (Ethicon Inc., Somerville, NJ, USA) on the medial and lateral sides of the tarsus. A suture was passed from the levator complex, about 7-12 $\mathrm{mm}$ from the tip, and horizontally threaded to the central part of the tarsus, and was passed back to the levator complex again (Figure 1C).

After removing the forceps, the suture was softly knotted (Figure 1D). Advancement and fixing were adjusted according to the condition when the patient's eyes were open. Intraoperative quantification (eyelid fissure, eyelid curvature, and lagophthalmos) was performed in the sitting position.

After the resection of excess tissue and skin, a double eyelid fold was formed and the skin closed with 6-0 Nylon ${ }^{\circledR}$ (Mani Co. Ltd. Inc., Tochigi, Japan).

\section{Image processing}

The following procedure was used to process images using Adobe Photoshop ${ }^{\circledR}$ (video graphic: https://www.youtube. com/watch?v=bJYtjGas_Ns\&feature=youtu.be).

Step 1: Start up Photoshop ${ }^{\circledR}$.

Step 2: Click on the image file and select "Open". Then click on the image in the specified folder and select "Open".
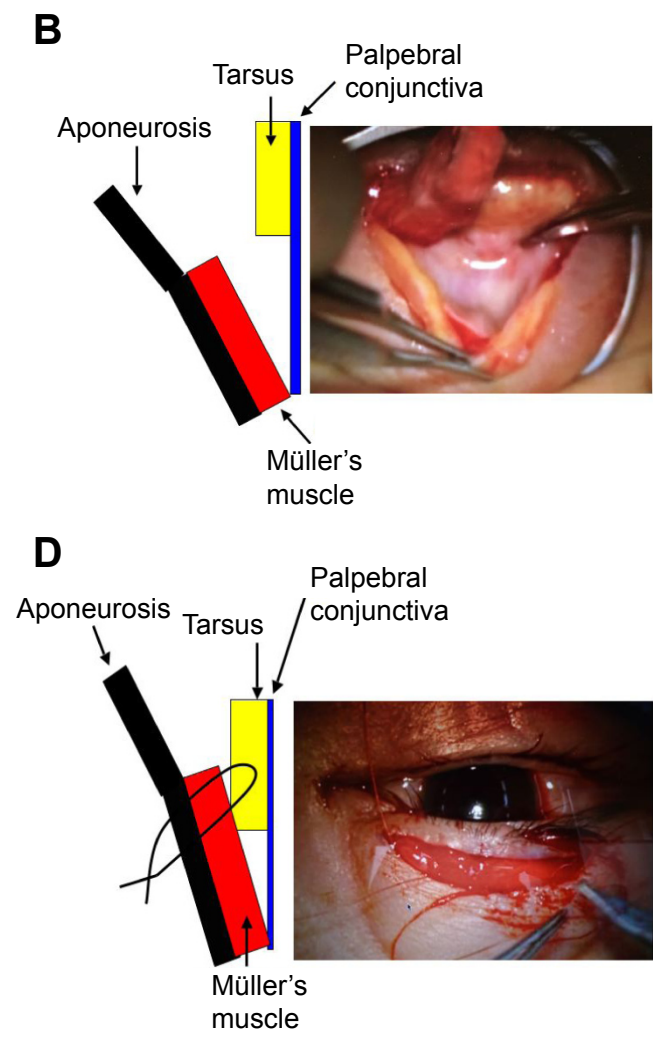

Figure I Surgical procedure (levator resection: surgeon's view).

Notes: (A) Detachment of levator aponeurosis from the tarsus. (B) Separation of levator aponeurosis and Müller's muscle complex from the palpebral conjunctiva. (C) Mattress suturing from the levator complex to the central part of the tarsus. (D) After removing the forceps, the mattress suture was softly knotted. 

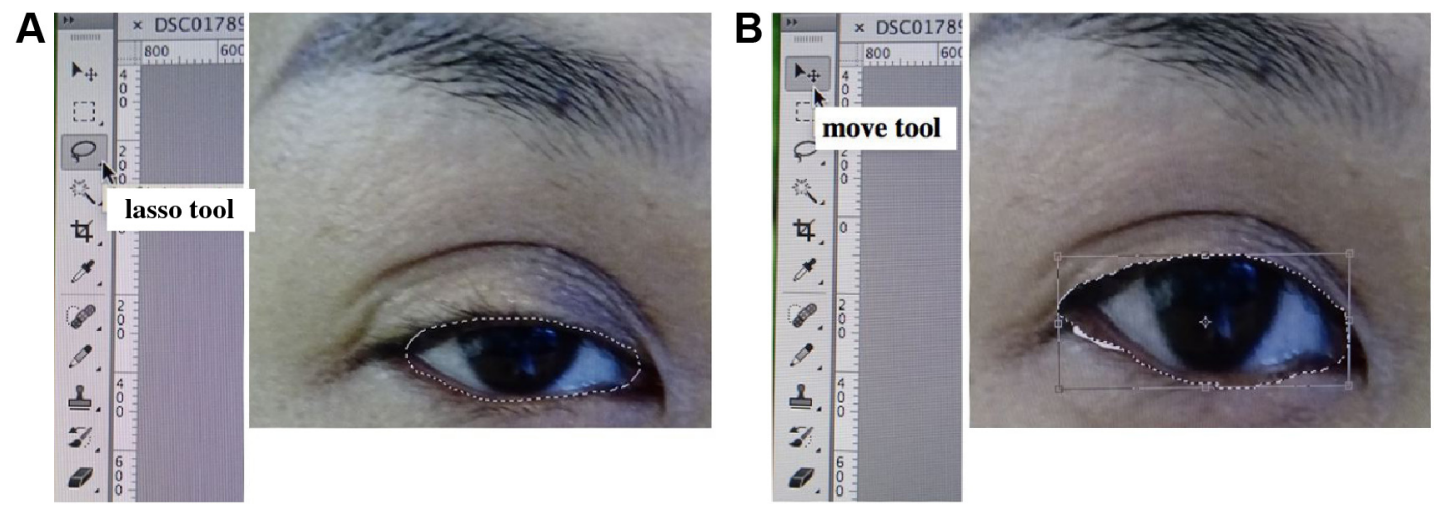

Figure 2 Image processing using Adobe Photoshop ${ }^{\circledR}$.

Notes: (A) Circumscribe the eye margin using the lasso tool. (B) Enlarge the selected eye margin using the move tool.

Step 3: Select the lasso tool on the left side of the operation toolbar (the third from the top) and circumscribe the eye margin (Figure 2A).

Step 4: Select the move tool on the left side of the operation toolbar (the top) and appropriately enlarge the selected eye margin. Using this tool, both vertical and horizontal changes can be made (Figure 2B).

Step 5: To save the image, click on the file and select "Save."

\section{Outcome measures Objective outcome}

Upper eyelid height was assessed before and after surgery using margin reflex distance-1 (MRD-1), which is defined as the distance from the central pupil reflex to upper eyelid margin, with eyes in the primary position. MRD-1 measurements taken preoperatively and at 1-month postoperatively were compared.

\section{Subjective outcome}

Approximately 1 month postoperatively, patients were asked to fill in questionnaires in order to evaluate whether they were satisfied with their postoperative appearance and whether the processed images to predict their postoperative appearance were useful.

\section{Results}

Mean ( \pm standard deviation [SD]) MRD-1 significantly increased from $0.67 \pm 0.75 \mathrm{~mm}$ (range -4 to $2 \mathrm{~mm}$ ) preoperatively to $3.47 \pm 0.60 \mathrm{~mm}$ (range $2-4.5 \mathrm{~mm}$ ) at 1 month postoperatively (paired $t$-test, $P<0.05$ ). No reduction in MRD-1 was observed during the follow-up in any patient.

Eyelid closure dysfunction of 1-2 $\mathrm{mm}$ occurred in six eyes (5.5\%), but improved within 3 months, and no patients exhibited persistent postoperative lagophthalmos. All patients required eye drops for dry eyes during the early postoperative period, although the condition improved steadily over time.

Four eyes exhibited skin redundancy following surgery, and thus required additional skin dermabrasion.

Approximately 1 month postoperatively, we asked patients whether they were satisfied with their postoperative appearance. Nineteen patients $(29.2 \%)$ were very satisfied and 39 patients $(60.0 \%)$ were satisfied. However, seven patients $(10.8 \%)$ were dissatisfied with their postoperative appearance.

Furthermore, we asked patients whether our predictive images were useful in gauging their postoperative appearance. Fifty-five patients (84.6\%) positively responded to the usefulness of the predictive images. However, some patients $(n=7,10.8 \%)$ were dissatisfied with their postoperative appearance, stating that predictive images were not useful.

The reasons given for such dissatisfaction included asymmetry of the eyelid fissure, eyelid thickness, and final appearance being different from the expected appearance. This level of dissatisfaction gradually improved, and no additional surgery was required

\section{Case report}

Case I

This was a 40-year-old woman who had been using hard contact lenses for 20 years. Surgical outcome was similar to that predicted by processed preoperative images (Figure 3A-C).

\section{Case 2}

This was an 80-year-old man with age-related blepharoptosis. Postoperative appearance was different from that predicted 

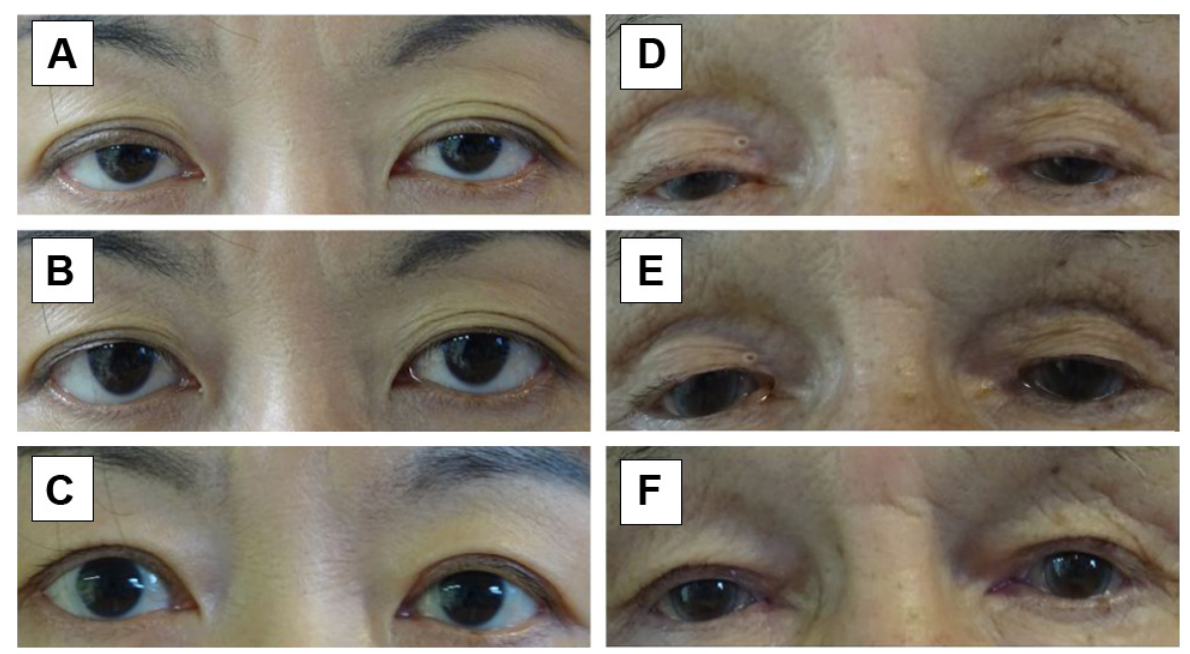

Figure 3 Case report of two patients.

Notes: (A, D) Preoperative condition. (B, E) Processed images predicting postoperative appearance. (C, F) Actual postoperative appearance at I month following levator resection.

by processed preoperative images due to a preoperative narrow eyelid fissure (Figure 3D-F).

\section{Discussion}

The predominant aim of blepharoptosis surgery is to improve visual fields or visual function. As eyelid elevation must be functionally stable, we routinely use Entropion Forceps during levator resection. The advantages of using forceps include good control of hemostasis by means of pressure and the prevention of eye injuries resulting from puncture during separation of Müller's muscles from the palpebral conjunctiva. However, anesthetization of the palpebral conjunctival fornix is required to prevent pain caused by pressure.

Although the choice of blepharoptosis surgery is controversial, levator resection is generally employed for patients with good levator function, while frontalis sling surgery is used for patients with poor levator function. ${ }^{1-4}$ Following the surgical procedures performed in this study, we observed significant improvement in postoperative MRD-1, even in cases with poor levator function. The British Oculoplastic Surgery Society National Ptosis Survey ${ }^{5}$ defined an operation as successful only if all of the following criteria were met: upper MRD between 3 and $5 \mathrm{~mm}$, interlid MRD difference $1 \mathrm{~mm}$ or less, and interlid crease difference $2 \mathrm{~mm}$ or less. The survey reported $65 \%$ of patients completely satisfied with the results. In our study, lower MRD postoperatively was observed in four eyes, and these were all cases with poor preoperative levator function. According to the British Oculoplastic Surgery Society National Ptosis Survey, 94\% of our surgical outcomes seemed to be successful. Stable postoperative eyelid extension was observed because of using forceps to completely separate the Müller's muscle from the conjunctiva and advance to the tarsus.

Although most questionnaire responses indicated that patients were satisfied with their postoperative appearance, a small number of patients were dissatisfied due to asymmetry of the eyelid fissure, eyelid thickness, and their appearance being different from the expected appearance.

Eyelid thickness is thought to result from weakened postoperative frontalis muscle function, which causes the position of eyebrow to drop and leads to thickening of the eyelids. Thus, particular caution may be required in cases where eyelid thickness is noted preoperatively.

During the early postoperative period, all of our patients required eye drops for dry eyes. As dry eye syndrome frequently occurs following blepharoptosis surgery, ${ }^{6,7}$ it is recommended that the surgeons pay adequate caution to avoid overcorrection.

Although functional improvement is most important, many patients undergoing blepharoptosis surgery were worried about their postoperative appearance. Blepharoptosis associated with the long-term use of hard contact lens is not uncommon in middle-aged women. ${ }^{8-10}$ Because many blepharoptosis patients in our institution were middle-aged women with prolonged use of hard contact lens, a particularly large number of our patients were worried about their postoperative appearance.

For this reason, we created predictive images to allow patients to anticipate postoperative appearance. Adobe Photoshop $^{\circledR}$ is a powerful photoediting and designing 
software, which is mainly used to correct imperfections and add special effects to digital images. Photoshop ${ }^{\circledR}$ is easy to obtain and allows the creation of reasonably accurate images of anticipated postoperative appearance.

Our predictive images were similar to actual surgical outcomes among cases with extended double eyelids, a feature commonly seen in patients with prolonged use of hard contact lens. In elderly patients and patients with a narrow eyelid fissure, surgical outcomes were somewhat different from predictions, as the size of cornea was enlarged in processed images. However, excluding a small number of patients who were not satisfied with their postoperative appearance, most responses indicated that our predictive images were useful, even in cases in which the postoperative appearance was different from the predicted images. Preoperative explanation followed by predictive images may reduce the concerns regarding postoperative appearance. Although preoperative explanation followed by a sketch or standard case before and after surgery pictures may be effective, predictive image processed from the patient's picture seems to be more persuasive.

In this software and our program, we were not able to produce accurate surgical outcomes, such as eyelid crease or corneal size. Also, unsuccessful results (such as under- or overcorrection, asymmetry of eyelid, and failed crease formation) shown to patients before surgery may be important. For this reason, we need to make various kinds of possible predictive images more accurately in the future.

In conclusion, predictive image photographs shown to patients prior to blepharoptosis surgery may be effective for those concerned with their postoperative appearance. This may serve as a useful tool to simulate blepharoptosis surgery.

\section{Disclosure}

The authors report no conflicts of interest in this work.

\section{References}

1. Wasserman BN, Sprunger DT, Helveston EM. Comparison of materials used in frontalis suspension. Arch Ophthalmol. 2001;119(5): 687-691.

2. Berry-Brincat A, Willshaw H. Paediatric blepharoptosis: a 10-year review. Eye (Lond). 2009;23(7):1554-1559.

3. Park DH, Choi WS, Yoon SH, Shim JS. Comparison of levator resection and frontalis muscle transfer in the treatment of severe blepharoptosis. Ann Plast Surg. 2007;59(4):88-392.

4. Buttanri IB, Serin D, Karslioglu S, Akbaba M, Ari S, Fazil K. Effect of suturing the silicon rod to the tarsal plate and the suture material used on success of frontalis suspension surgery. Ophthal Plast Reconstr Surg. 2013;29(2):98-100.

5. Scoppettulol E, Chadha V, Bunce C, Olver JM, Wright M. British Oculoplastic Surgery Society (BOPSS) National Ptosis Survey. Br J Ophthalmol. 2008;92(8):1134-1138.

6. Watanabe A, Kakizaki H, Selva D, et al. Short-term changes in tear volume after blepharoptosis repair. Cornea. 2014;33(1):14-17.

7. Mehta VJ, Perry JD. Blepharoptosis repair outcome from trainee versus experienced staff as the primary surgeon. Am J Ophthalmol. 2013; 155(2):397-403.e1.

8. Epstein G, Putterman AM. Acquired blepharoptosis secondary to contact-lens wear. Am J Ophthalmol. 1981;91(5):634-639.

9. van den Bosch WA, Lemij HG. Blepharoptosis induced by prolonged hard contact wear. Ophthalmology. 1992;99(12):1759-1765.

10. Watanabe A, Araki B, Noso K, Kakizaki H, Kinoshita S. Histopathology of blepharoptosis induced by prolonged hard contact lens wear. Am J Ophthalmol. 2006;141(6):1092-1096.
Clinical Ophthalmology

\section{Publish your work in this journal}

Clinical Ophthalmology is an international, peer-reviewed journal covering all subspecialties within ophthalmology. Key topics include: Optometry; Visual science; Pharmacology and drug therapy in eye diseases; Basic Sciences; Primary and Secondary eye care; Patient Safety and Quality of Care Improvements. This journal is indexed on

Submit your manuscript here: http://www.dovepress.com/clinical-ophthalmology-journal

\section{Dovepress}

PubMed Central and CAS, and is the official journal of The Society of Clinical Ophthalmology (SCO). The manuscript management system is completely online and includes a very quick and fair peer-review system, which is all easy to use. Visit http://www.dovepress.com/ testimonials.php to read real quotes from published authors. 